\title{
Mixed Adenocarcinoma-Carcinoid (Collision Tumor) of the Appendix
}

\author{
Naorem Gopendro Singh ${ }^{a}$ Abul Ala Syed Rifat Mannan ${ }^{a}$ Mirza Kahvic ${ }^{a}$ \\ Ali Mohamd Nur ${ }^{b}$ \\ Departments of a Pathology and b Surgery, Al-Jahra Hospital, Al-Jahra, Kuwait
}

\section{Key Words}

Adenocarcinoma - Appendix · Carcinoid · Collision tumor • Composite tumor $\cdot$ Mixed tumors

\begin{abstract}
Objective: To report a case of mixed adenocarcinoma and carcinoid in the gastrointestinal tract. Clinical Presentation and Intervention: A 52-year-old man presented with a mass at the base of the appendix. On microscopic examination of the tumor, mixed adenocarcinoma and carcinoid was identified. The carcinoid component was insular/trabecular in morphology, and the epithelial component revealed mucinous adenocarcinoma. Morphologically and immunohistochemically the 2 components showed a clear-cut distinction, without any intervening intermediate cell population. The adenocarcinomatous component displayed omental deposit and metastasis to the regional lymph nodes. One year later, the patient developed multiple metastatic deposits of adenocarcinoma in the liver, rectus muscle, ileum and sigmoid colon. Conclusion: This tumor had an aggressive clinical course and behaved more like adenocarcinoma than carcinoid.

Copyright $\odot 2011$ S. Karger AG, Basel
\end{abstract}

\section{Introduction}

Mixed glandular-endocrine neoplasms, composed of carcinoid tumor in one area and adenoma/adenocarcinoma in another, are unusual tumors of the digestive tract [1]. When both the epithelial tumor and neuroendocrine tumor are present in the same area without any transitional changes in the tumor cells, they are termed as 'collision' tumors. The designation of 'composite' tumor is reserved for those tumors exhibiting transition or intermediate cells between the 2 components [2]. Collision tumors are considered to be a biclonal derivation, resulting from 2 separate but adjacent neoplasms, while composite tumors are believed to result from multidirectional differentiation of a single neoplasm $[2,3]$. However, from a practical point of view, a clear-cut morphological distinction may not be attained in all cases.

Collision tumors composed of a carcinoid and mucinous adenocarcinoma are rare in the appendix. Here, we describe a case of collision tumor of the appendix, with metastatic deposits of the carcinomatous component in the lymph node, omentum, liver, ileum and sigmoid colon.

\section{KARGER \\ Fax +4161306 1234 \\ E-Mail karger@karger.ch}

www.karger.com
(C) 2011 S. Karger AG, Basel

1011-7571/11/0204-0384\$38.00/0

Accessible online at:

www.karger.com/mpp
Dr. Naorem Gopendro Singh

Department of Pathology, Al-Jahra Hospital

PO Box 62276

Al-Jahra 02153 (Kuwait)

Tel. +9659712 8990, E-Mail gopen71@yahoo.co.in 

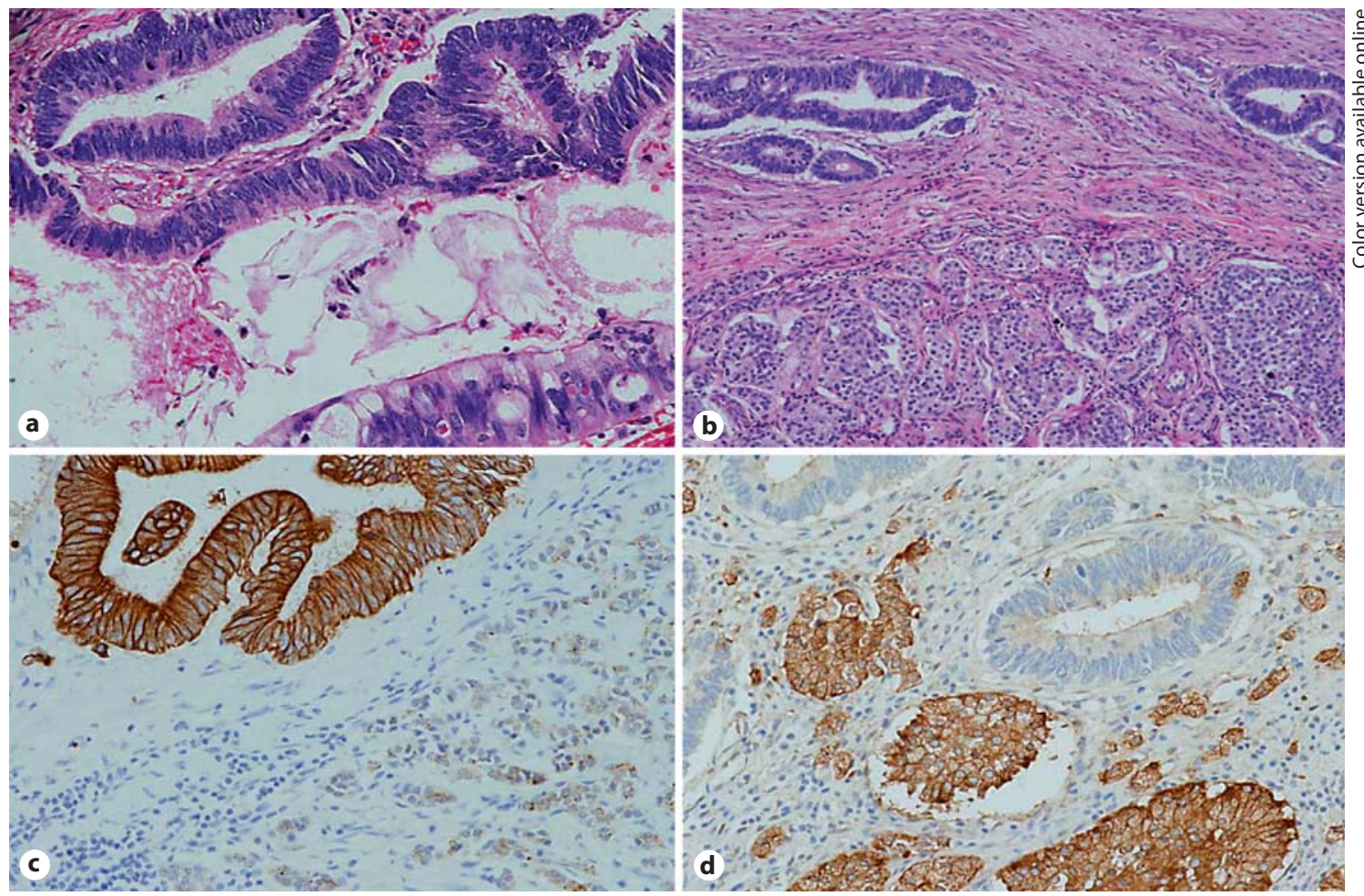

Fig. 1. Photomicrographs showing the dual tumor component. a Adenocarcinoma reveals pleomorphic tumor cells arranged in a glandular pattern in a pool of extracellular mucin. HE. $\times 200$. b Carcinoid tumor cells display the nesting pattern separated by fibrovascular septa with adjacent component of adenocarcinoma.

\section{Case Report}

A 52-year-old man presented with a 6-month history of progressive abdominal discomfort and frequent pain in the right lower quadrant. He also complained of constipation and weight loss. On examination, a palpable mass was identified in the right iliac fossa. His laboratory investigation revealed raised liver enzymes, mild anemia and elevated serum carcinoembryonic antigen (560 $\mathrm{ng} / \mathrm{ml}$; normal range $0.3-2.7 \mathrm{ng} / \mathrm{ml}$ ). Ultrasound examination of the abdomen revealed a hypoechoic mass at the ileocecal junction, measuring about $6 \times 5 \mathrm{~cm}$. Computerized tomography exhibited the same mass at the ileocecal junction encasing the base of the appendix. Colonoscopy showed no luminal mass at the cecum, but there was an impression of mass outside the bowel lumen at the ileocecal junction. The patient underwent right hemicolectomy with excision of the omental deposit.

Gross pathological examination revealed a mass at the ileocecal junction measuring $6 \times 5 \times 5 \mathrm{~cm}$, involving the base of the appendix. A cut section of the mass was gelatinous, with a focal area of necrosis. Another small mucosal protrusion was identified at the base of the appendix, juxtaposed to the previous tumor. Microscopically, 2 tumor components were noted. The predominating component showed pools of mucin with dispersed pleomorphic tumor cells forming acini (fig. 1a) and in places forming diffuse sheets. The other component exhibited sheets of uniform tumor cells arranged in nests and in a trabecular pattern with fine
HE. $\times 200$. c Immunohistochemistry showing cytokeratin positivity in adenocarcinoma and focal dot-like positivity in the carcinoid component. d Chromogranin A positivity in the carcinoid tumor. Avidin biotin peroxidase. $\times 200$. nuclear chromatin (fig. 1b). There was no transition or intermediate cell between the 2 tumor components.

Immunohistochemistry revealed the mucinous tumor to be reactive for cytokeratin (polyclonal wide spectrum, Dako, USA; fig. 1c) and carcinoembryonic antigen (polyclonal rabbit anti-human, Dako, Denmark A/S). The carcinoid tumor displayed granular cytoplasmic positivity to chromogranin A (clone DAK-A3, Dako, Denmark A/S; fig. 1d) and synaptophysin (rabbit-polyclonal, Cell Marque, USA) and dot-like positivity to cytokeratin. A diagnosis of collision tumor of the appendix with features of mucinous adenocarcinoma and carcinoid tumor was made. Both components showed transmural infiltration of the wall of the appendix. The adenocarcinoma component showed metastatic deposits in the regional lymph nodes (2/13) and omentum. The patient made an uneventful recovery and was referred to the Cancer Centre for further treatment. At the Cancer Centre, the patient received 6 cycles of oxaliplatin, 5 -fluorouracil and leukovorin followed by bevacizumab and irinotecan (CPT11). No radiotherapy was given. Six months after the chemotherapy, the patient presented with symptoms of intestinal obstruction and underwent a small-bowel resection, which revealed multiple serosal deposits of mucinous adenocarcinoma. During surgery, additional biopsies were taken from the suspected liver, omentum and rectus muscle, and the biopsies documented metastatic adenocarcinoma. The patient died of multiple metastatic disease 8 months after the second operation. 


\section{Discussion}

Mixed adenoendocrine patterns characterize rare tumors of the digestive tract. The first description dates back as far as 1924 [4]. A greater number of cases are reported in the appendix [1], which is also the most common location of carcinoid tumors of the gastrointestinal tract. Most of these cases are reported as adenocarcinoids/goblet cell carcinoid [1]. Edmonds et al. [5] reported the largest series of 86 cases of goblet cell carcinoid of the appendix. Carr et al. [6] described 13 cases of dual carcinoid/epithelial neoplasia occurring in the appendix. Recently Jain and Das [7] described a collision tumor involving the terminal ileum and cecum. To our knowledge, 'collision tumor' has not been reported in the appendix to date except for a single case reported by Rossi et al. [8], in which adenocarcinoma was associated with small-cell carcinoma.

The histogenesis of composite/collision tumors has not been fully elucidated. Despite the recognition of the common embryonic origin for both the collision and composite tumors [9], composite tumors are considered to be derived from a single event in which the initial neoplastic clone undergoes divergent differentiation, while collision tumors are considered to be of biclonal derivation, resulting from 2 separate but adjacent neoplasms [9]. However, this classification is not universally accepted since the cell of origin is still not very clear [1].

Histologically, collision tumors have been distinguished from composite tumors in that the components, although intimately juxtaposed, are not intermixed and do not show transition [2]. In addition a single tumor component should be observed in the metastases [2], as noted in the present case. Conversely 'composite tumor' is used when the endocrine and epithelial cells are intermixed within the same tissue and transitions can be observed [2]. Both glandular and carcinoid elements should be present in metastases from composite tumors [2]. In the present case, the carcinoid component and adenocarcinoma component were juxtaposed without any evidence of transition between the two components. Metastatic deposits showed the presence of only the adenocarcinoma component.

The prognosis of a composite/collision tumor remains a matter of debate. Contrary to former belief, composite tumors do not appear to have a better prognosis than ordinary adenocarcinoma $[10,11]$. In the present case, it is the adenocarcinoma component which demonstrated aggressive behavior with the presence of multiple metastatic deposits. In their review of 86 cases of composite tumors in the appendix, Edmonds et al. [5] found that 51 subjects were free of disease, 3 had persistent disease, and 11 died of disease following treatment by colectomy or appendectomy alone. Composite tumors occurring elsewhere in the gastrointestinal tract have also been shown to behave more aggressively. Levendoglu et al. [1] documented 6 cases of gastrointestinal composite tumors, out of which 2 subjects with cecal tumors died of metastatic disease 3 and 9 months after surgery. Therefore, patients with composite/collision tumor have to be approached and treated more like patients with carcinoma than carcinoid.

\section{Conclusion}

This tumor had an aggressive clinical course and behaved more like adenocarcinoma than carcinoid.

\section{References}

$>1$ Levendoglu H, Cox CA, Nadimpalli V: Composite (adenocarcinoid) tumors of gastrointestinal tract. Dig Dis Sci 1990;35:519-525.

$>2$ Lewin K: Carcinoid tumors and the mixed (composite) glandular-endocrine cell carcinomas. Am J Surg Pathol 1987;11(suppl 1):71-86.

3 Pecorella I, Memeo L, Ciardi A, Rotterdam $\mathrm{H}$ : An unsual case of colonic mixed adenoendocrine carcinoma: collision versus composite tumor. A case report and review of the literature. Ann Diagn Pathol 2007;11:285-290.

4 Cordier R: Les cellules argentaffines dans les tumeurs intestinales. Arch Int Med Exp 1924;1:59-63.

$\checkmark 5$ Edmonds P, Merino MJ, Li Volsi VA, Duray $\mathrm{PH}$ : Adenocarcinoid (mucinous carcinoid) of the appendix. Gastroenterology 1984;86: 302-309.

6 Carr NJ, McCarthy WF, Sobin LH: Epithelial noncarcinoid tumors and tumor-like lesions of the appendix. Cancer 1995;75:757768.

7 Jain M, Das KK: Concurrent occurrence of terminal ileum carcinoid tumor and cecal adenocarcinoma: a collision tumor or composite tumor? Indian J Pathol Microbiol 2009;52:285-286.

$>8$ Rossi G, Bertolini F, Sartori G, Bigiani N, Cavazza A, Foroni M, Valli R, Rindi G, De Gaetani C, Luppi G: Primary mixed adenocarcinoma and small cell carcinoma of the appendix: a clinicopathologic, immunohis- tochemical, and molecular study of a hitherto unreported tumor. Am J Surg Pathol 2004;28:1233-1239.

-9 Goldenberg DM, Fisher ER: Histogenetic relationship between carcinoid and mucin-secreting carcinomas of colon as revealed by heterotransplantation. Br J Cancer 1970;24: 610-614.

10 Rogers LW, Murphy RC: Gastric carcinoid and gastric carcinoma: morphologic correlates of survival. Am J Surg Pathol 1979;3: 195-202.

11 Murayama H, Imai T, Kikuchi M: Solid carcinomas of the stomach: A combined histochemical light and electron microscopic study. Cancer 1983;51:1673-1681. 